\title{
An Integrated Model of Pathological Complete Response and Postoperative CEA Predicts Survival and Benefit of Adjuvant Chemotherapy for Locally Advanced Rectal Cancer
}

\section{Shu-Biao Ye}

Sun Yat-sen University Sixth Affiliated Hospital

\section{Dong-Wen Chen}

Sun Yat-sen University Sixth Affiliated Hospital

\section{Pei-Si Li}

Sun Yat-sen University Sixth Affiliated Hospital

Zhen-Sen Lin

Sun Yat-sen University Sixth Affiliated Hospital

Jia-Hui Long

Sun Yat-sen University Sixth Affiliated Hospital

Yi-Kan Cheng ( $\nabla$ chengyk3@mail.sysu.edu.cn)

Sun Yat-sen University Sixth Affiliated Hospital https://orcid.org/0000-0001-6801-794X

\section{Ping Lan}

Sun Yat-sen University Sixth Affiliated Hospital

\section{Primary research}

Keywords: locally advanced rectal cancer, pathological complete response, postoperative CEA, prognostic model, adjuvant chemotherapy, distant metastasis-free survival

Posted Date: June 2nd, 2021

DOl: https://doi.org/10.21203/rs.3.rs-546136/v1

License: (c) (1) This work is licensed under a Creative Commons Attribution 4.0 International License. Read Full License 


\section{Abstract \\ Background:}

Pathological complete response (PCR) and postoperative carcinoembryonic antigen (CEA) respectively represent pathological and biological response to treatment and prognostic indictors for locally advanced rectal cancer. However, the prognostic significance of integrated PCR and postoperative CEA model is rarely investigated.

\section{Methods:}

This big-data intelligence platform-based cohort biomarker study extracted clinicopathological characteristics and postoperative CEA of 919 locally advanced (clinical stage II-III) rectal cancer patients receiving neoadjuvant treatment from 6125 cases between April 2011 through September 2018 at Sun Yat-sen University, the Sixth Affiliated Hospital. An integrated model was constructed using pCR combined with the cut-off value of postoperative CEA generated from the receiver operating characteristic (ROC) curve. The model stratified locally advanced rectal cancer patients into four groups.

\section{Results:}

Both pathological response-pCR and biological response-postoperative CEA were independent prognostic indicators. In all patients, the 3-year distant metastasis-free survival (DMFS) $(70.0 \%)$ and disease-free survival (DFS) (64.8\%) rates were significantly lower in patients without $\mathrm{pCR}$ and postoperative CEA > $2.78 \mathrm{ng} / \mathrm{ml}$ (all $\mathrm{p}$ values $<0.05$ ). Among patients treated with $<3$ months of postoperative adjuvant chemotherapy (ACT), all others had higher 3-year DMFS and DFS rates. Among patients receiving $\geq 3$ months of ACT, those without pCR had similar 3-year DMFS rates regardless of postoperative CEA level.

\section{Conclusions:}

The response integrated model with $\mathrm{PCR}$ and postoperative CEA not just effectively predict DMFS and DFS in locally advanced rectal cancer patients, but also was a predictive tool to potentially modify the optimal duration of ACT for locally advanced rectal cancer patients.

\section{Introduction}

With the introduction of preoperative chemoradiotherapy (CRT) and standardized total mesorectal excision (TME), a milestone surgical technique, locoregional control has greatly improved with local recurrence rate of $7 \%-10 \%$ for locally advanced rectal cancer patients, while the distant control is not promising ${ }^{1-4}$. Therefore, distant metastasis has currently become the major challenge for disease failure. The American Joint Committee on Cancer/the International Union Against Cancer (AJCC/UICC) tumor- 
node-metastasis (TNM) staging system is the key determinant in aiding diagnosis, monitoring treatment decisions and predicting prognosis including distant metastasis ${ }^{5}$. However, among rectal cancer patients within the same staging categories, survival patterns, especially metastasis, vary widely ${ }^{6,7}$. Thus, great efforts have been undertaken to determine the prognostic significance of potential biomarkers.

The degree of response to neoadjuvant treatment appears to be a prognosticator of survival in locally advanced rectal cancer ${ }^{8}$. Strong evidence exists that complete eradication of the tumor, which was defined as pathologic complete response (pCR), has been associated with better overall and disease-free survival ${ }^{9,10}$. Almost $20 \%$ of patients responded well to neoadjuvant treatment and achieved pCR, who had a lower risk of developing distant metastases ${ }^{11,12}$. Carcinoembryonic antigen (CEA) levels has been considered to be level I prognostic marker. Thus, some investigators have suggested that it be a supplement for the TNM staging system ${ }^{13-15}$. Not only patients with elevated pretreatment CEA ${ }^{15,16}$ but also postoperative CEA are associated with higher rates of distant metastases ${ }^{17,18}$. Moreover, postoperative CEA level could be a biological indicator for treatment response.

Although pCR and postoperative CEA represent promising pathologic and biological biomarkers to predict treatment response and distant metastasis, there is a paucity of data to cooperate $\mathrm{PCR}$ and postoperative CEA into an integrated model. Postoperative adjuvant chemotherapy (ACT) has been the routine use based on an extrapolation of colon cancer patients ${ }^{19-21}$; however, the role of ACT in locally advanced rectal cancer is questioned due to the improvement of imaging, neoadjuvant treatment, and routine use of $\mathrm{TME}^{22,23}$. Therefore, there is great demand to identify whether integration of $\mathrm{pCR}$ and postoperative CEA model after curative resection could effectively predict metastasis and survival outcomes among patients in different ACT duration groups. The aim of the present study was to develop and assess an integrated pCR and postoperative CEA prognostic model.

\section{Method}

\section{Data extraction and patient cohort}

Consecutive patients who received neoadjuvant treatment and curative resection for clinical stage II-III rectal cancer were extracted from the prospectively maintained databases from April 2011 through September 2018 at Sun Yat-sen University, the Sixth Affiliated Hospital. Then we reviewed their clinical data from a big-data intelligence platform which had aggregated data from numerous hospital information systems (eg, admission, discharge, and transfer), electronic medical records, resource information systems (pathology, laboratory information), and endoscopy, ultrasound, and electrocardiography systems. The exclusion criteria for patients was lack of postoperative CEA. This study was approved by the Institutional Review Board of Sun Yat-sen University, the Sixth Affiliated Hospital and followed the reporting recommendation of tumor marker studies (REMARK) guidelines. All patients signed informed consent before the treatment.

\section{CEA assessment and definition of pCR}


Postoperative CEA was defined as the latest CEA value checked within 3 months after operation and before the initiation of ACT. Serum CEA was assayed at our institution using a Tosoh automated analyzer (TOSOH Inc., Tokyo, Japan). The reference range for pretreatment CEA was 0.0 to $5.0 \mathrm{ng} / \mathrm{mL}$. Two gastrointestinal pathologists reviewed the surgical specimen independently according to the routine procedure of our institution. pCR was defined as no residual tumor cell in primary tumor and regional lymph nodes.

\section{Treatment}

All patients received neoadjuvant treatment and curative resection. Fluorouracil -based chemotherapy was delivered concurrently with radiation. Radiation was delivered at 1.8 to 2.0 Gy per day with a total of 23 to 25 fractions (total dose, 46.0 to $50.4 \mathrm{~Gy}$ ). The clinical target volume (CTV) included the mesorectal facia region, lymphatic drainage areas, i.e., mesorectal, internal iliac, and presacral lymph nodes. The regimens of neoadjuvant chemotherapy alone were mFOLFOX6 (fluorouracil and oxaliplatin) and FOLFOXIRI (fluorouracil, oxaliplatin and irinotecan) as FOWARC ${ }^{24}$ and FORTUNE ${ }^{25}$ clinical trial described.

\section{Follow-up and statistical analysis}

Follow-up duration was measured from the first day of treatment to either the day of death or the day of last follow-up. Surveillance of patients included physical examination, interval history, serum CEA testing, imaging and colonoscopy. Patients were followed every 3-6 months during the first 2 to 3 years, and every 1 year thereafter. Distant metastasis-free survival (DMFS) or local recurrence-free survival (LRFS)was defined as the duration of the first day of treatment to the day of distant or local recurrence. Disease-free survival (DFS) was defined as time to the date of confirmed relapse of disease or death.

SPSS 22.0 (SPSS, Inc, Chicago, IL) was used to perform all statistical analyses. The cut-off point for postoperative CEA level was determined using the receiver operating characteristics (ROC) curve analysis. Mann-Whitney $U$ test and $\chi 2$ test (or Fisher's exact test, if appropriate) was used to compare continuous clinical variables and categorical data, respectively. Univariable survival was compared using the log-rank test and Kaplan-Meier curves was used to generate time-to-event data. The Cox multivariate proportionalhazards regression analysis was used to calculate $P$ values, hazard ratios (HRs), and 95\% confidence intervals (Cls). Clinical characteristics (age, gender, BMI, $\mathrm{T}$ and $\mathrm{N}$ categories, postoperative CEA, $\mathrm{pCR}$ and ACT) were included as covariates. Two-side $p$-value less than 0.05 was considered significant.

\section{Results}

\section{Clinical characteristics and patient outcomes}

Clinical characteristics of patients were shown in Table 1. A total of 1065 patients who received neoadjuvant treatment and curative resection for clinical stage II-III rectal cancer patients were identified from the big-data intelligence platform. One hundred forty-six patients were excluded due to the lack of postoperative CEA, which mainly caused by loss of follow-up examination. Among the remaining 919 patients, 650 (70.7\%) patients were male and the median (IQR) age was 55 (19-88) years old. The 
median (IQR) preoperative and postoperative CEA value was $3.83 \mathrm{ug} / \mathrm{ml}(0.5-705.3 \mathrm{ug} / \mathrm{ml})$ and 1.54 $\mathrm{ug} / \mathrm{ml}(0.5-54.1 \mathrm{ug} / \mathrm{ml})$, respectively. The median (IQR) body mass index (BMI) was $22.5 \mathrm{~kg} / \mathrm{m}^{2}(12.8-$ $\left.34.9 \mathrm{~kg} / \mathrm{m}^{2}\right)$. A total of $170(18.5 \%)$ patients achieved pCR after neoadjuvant treatment. Median (IQR) duration of follow-up was 33.3 months (4.4-106.4 months). A total of $184(19.7 \%)$ patients developed distant metastases, and $72(7.8 \%)$ patients died and 5 of them died of non-cancer causes. Sixty-four patients (7.0\%) developed local or regional recurrence. The 3-year DMFS, DFS, and LRFS rates for all patients were $77.5 \%, 72.9 \%$, and $92.4 \%$, respectively. 
Table 1

Clinicopathological characteristics of patients with locally advanced rectal cancer $(n=919)$

\section{Characteristics}

\section{Gender}

Male

Female

Age (y)

$<60$

$\geq 60$

Comorbidity

Yes

No

Clinical T stage ${ }^{\star}$

$\mathrm{T} 1$

$\mathrm{T} 2$

T3

$\mathrm{T} 4$

NA

Clinical $\mathbf{N}$ stage ${ }^{\star}$

NO

N1

N2

NA

\section{Clinical stage}

II

III

NA

Distance from anal verge

*According to the 8th American Joint Committee on Cancer/Union for International Cancer Control (AJCC/ UICC) of the staging system.
No of patients $(\%)$

$650(73.5)$

$269(26.5)$

$577(72.6)$

$342(27.4)$

$190(58.8)$

$729(41.2)$

$1(0.1)$

$33(3.6)$

691 (75.2)

193 (21.0)

1 (0.1)

192 (20.9)

432 (47.0)

293 (31.9)

2 (0.2)

192 (20.9)

725 (78.9)

2 (0.2) 


\begin{tabular}{|ll|}
\hline Characteristics & No of patients (\%) \\
\hline$\leq 5 \mathrm{~cm}$ & $430(46.8)$ \\
\hline$>5$ and $\leq 10 \mathrm{~cm}$ & $421(45.8)$ \\
$>10 \mathrm{~cm}$ & $65(7.1)$ \\
\hline NA & $3(0.3)$ \\
\hline Differentiation & \\
\hline Well & $524(57.0)$ \\
\hline Moderately & $230(25.0)$ \\
\hline Poorly & $109(11.9)$ \\
\hline NS & $56(6.1)$ \\
\hline Adjuvant chemotherapy (ACT) & $104(11.3)$ \\
\hline No & $366(39.8)$ \\
\hline$<6$ cycles & $449(48.9)$ \\
\hline$\geq 6$ cycles & \\
\hline *According to the 8th American Joint Committee on Cancer/Union for International Cancer Control \\
(AJCC/ UICC) of the staging system.
\end{tabular}

\section{Identification of the postoperative CEA cut-off value}

Since postoperative CEA could normalize after neoadjuvant treatment and curative resection for the vast majority of patients, we attempted to identify the optimal cut-off point to investigate the prognostic value of postoperative CEA. The cut-off value of postoperative CEA was identified using the ROC curve. The points were $1.18 \mathrm{ng} / \mathrm{ml}$ for DMFS [AUC (area under the ROC) $=0.544, \mathrm{p}<0.05$ ] and $2.78 \mathrm{ng} / \mathrm{ml}$ for DFS $(A U C=0.547, p<0.05)$, respectively. According to a multi-institution analysis, the cut-off value for postoperative CEA for DMFS was $2.5 \mathrm{ng} / \mathrm{ml}^{26}$. Therefore, a uniform cutoff value of $2.78 \mathrm{ng} / \mathrm{ml}(>2.78$ $\mathrm{ng} / \mathrm{ml}$ versus $\leqslant 2.78 \mathrm{ng} / \mathrm{ml}$ ) was selected from DFS to stratify patients into high and low postoperative CEA groups. Both postoperative CEA cut-off value and pCR were significant prognostic indicators for DMFS and DFS (Table S1).

\section{Prognostic value of pCR and postoperative CEA cut-off points}

The 3-year DMFS (Fig. 1a), DFS, and LRFS rates for patients with pCR and without pCR were $95.8 \%$ versus $73.3 \%, 92.9 \%$ versus $68.4 \%$, and 96.5 versus $91.4 \%$, respectively (all p-values $<0.01$ ). The 3 -year DMFS (Fig. 1C), DFS, and LRFS rates for patients with a postoperative CEA $\leqslant 2.78$ and $>2.78 \mathrm{ng} / \mathrm{ml}$ were 
$79.0 \%$ versus $70.1 \%, 75.8 \%$ versus $58.9 \%$, and $94.0 \%$ versus $84.6 \%$, respectively (all p-values $<0.05$ ). Altogether, patients with pCR or postoperative CEA $\leqslant 2.78 \mathrm{ng} / \mathrm{ml}$ had better DMFS, DFS, and LRFS.

\section{Integrated model of the PCR and postoperative CEA}

To determine whether PCR plus postoperative CEA would be a more efficient tool to predict prognosis than either one alone, patients with locally advanced rectal cancer were assigned into four groups as follows: Group 1 (pCR and postoperative CEA $\leqslant 2.78 \mathrm{ng} / \mathrm{ml}$ ), Group 2 (pCR and postoperative CEA > 2.78 $\mathrm{ng} / \mathrm{ml}$ ), Group 3 (without pCR and postoperative CEA $\leqslant 2.78 \mathrm{ng} / \mathrm{ml}$ ), and Group 4 (without pCR and postoperative CEA $>2.78 \mathrm{ng} / \mathrm{ml}$ ). The prognostic validity was compared using ROC curves. The AUCs of DMFS for pCR and postoperative CEA were 0.588 and 0.528 , respectively, and rose to 0.621 when these two variables were integrated (all $p$ values $<0.05$, Fig. 2 ).

\section{The prognostic value of the integrated model}

The 3-year DMFS rates for the patients among Groups $1-4$ were $98.0 \%, 94.6 \%, 79.5 \%$, and $70.0 \%$, respectively. And the 3-year DFS rates of $98.0 \%, 90.0 \%, 84.6 \%$, and $64.8 \%$, respectively. Group 4 patients had the worst 3-year DMFS (Fig. 3a) and DFS (Figure S1a) rates among the four groups (all $p$-values < 0.01 ), while patients in Group 3 had the second lowest rates (all $p$-values $<0.05$ ). There was no significant difference between Group 1 and Group 2 in terms of the 3-year DMFS or DFS rates $(p=0.413$ and $p=0$. 195).

The prognostic value of the integrated model for patients with different duration of ACT ( $<3$ months, and $\geq 3$ months of $A C T$ cohort)

One hundred and four patients refused to receive adjuvant chemotherapy. The adherence to ACT after neoadjuvant treatment and surgery is poor and the median duration of ACT is 3 months. As the benefit of the use and intensity of ACT in the setting of neoadjuvant treatment followed by surgery remains unclear, the prognostic significance of the integrated model were further investigated among patients stratified by different duration of ACT (no ACT, $<3$ months, and $\geq 3$ months ). Since only 104 patients did not receive $A C T$, the trend was not obvious when patients were divided into 4 groups. For patients receiving $<3$ months of ACT, the 3-year DMFS (Fig. 3b), and DFS (Supplementary Figure S1b) rates for patients in Groups 1 to 3 were $100.0 \%$ versus $95.1 \%$ versus $79.9 \%, 100.0 \%$ versus $90.1 \%$ versus $72.2 \%$, and $95.5 \%$ versus $91.7 \%$ versus $77.5 \%$ respectively (all $p$-values $>0.05$ ). The 3 -year DMFS (Fig. $3 b$ ), and DFS (Supplementary Figure $\mathrm{S} 1 \mathrm{~b})$ rates $(68.3 \%$, and $63.6 \%$, respectively, all $p$-values $<0.05)$ were the lowest for Group 4.

For patients receiving $\geq 3$ months of ACT, patients in Group 4 had the lower 3-year DMFS rates than those of Group 1 and Group 2, (70.0\% versus $91.7 \%, 70.0 \%$ versus $95.5 \%$, all $p$-values $<0.05)$. However, patients in Group 3 and Group 4 had similar 3-year DMFS rates (70.0\% versus 77.5\%, $p>0.05$ ) (Fig. 3c). Moreover, Group 4 patients had the lowest 3-year DFS (Supplementary Figure S1c) rate (64.4\%) in all four groups (all $p$-values < 0.05). Group 3 patients had lower 3-year DFS rates than patients among Group 1 and 2 
(74.6\% versus $95.5 \%, 74.6 \%$ versus $91.7 \%$; all $p$-values $<0.05)$, whose 3 -year DFS rates were similar ( $p$ values $>0.05)$.

Both pCR and postoperative CEA were independent and significant prognostic indicators in multivariate analysis for DMFS and DFS in patients receiving $\geq 3$ months of ACT and for DFS in patients with $<3$ months of $A C T$, while only $\mathrm{PCR}$ was independent predictor for DMFS in patients treated with $<3$ months of ACT. (Table 2).

Table 2

Multivariate analysis of the prognostic factors for distant recurrence-free survival and disease-free survival of patients with $<3$ months and $\geq 3$ months of adjuvant chemotherapy

Endpoints variable $\mathrm{HR}(95 \% \mathrm{Cl}) \quad p$ value

Patients with $<6$ cycles of ACT

Distant recurrence-free survival
PCR
$9.116(2.229-37.284)$
0.002

Disease-free survival

\begin{tabular}{lll} 
pCR & $4.306(1.738-10.669)$ & 0.002 \\
\hline Postop CEA & $1.864(1.132-3.069)$ & 0.014
\end{tabular}

Patients with $\geq 6$ cycles of ACT

Distant recurrence-free survival

\begin{tabular}{lll} 
pCR & $3.444(1.506-7.880)$ & 0.003 \\
\hline Postop CEA & $1.766(1.074-2.903)$ & 0.025
\end{tabular}

Disease-free survival

\begin{tabular}{lll} 
pCR & $4.146(1.821-9.441)$ & 0.001 \\
\hline Postop CEA & $1.984(1.273-3.091)$ & 0.002
\end{tabular}

pCR, pathologic complete response; postop CEA, postoperative carcinoembryonic antigen;

The following variables were included in the Cox proportional hazards model by backward elimination: age ( $\geq 60$ versus $<60$ years), gender (male versus female), clinical T category (T4 versus $\mathrm{T} 1-3)$, clinical $\mathrm{N}$ category (N2 versus $\mathrm{N} 1$ versus $\mathrm{N} 0$ ), postop CEA (>2.78 versus $\leqslant 2.78 \mathrm{ng} / \mathrm{ml}$ ) and pCR (with versus without).

\section{Discussion}


Applying neoadjuvant treatment and improved surgical technique- TME in locally advanced rectal cancer, local disease control has greatly improved during recent decades, while distant metastasis is now the leading cause of disease failure ${ }^{1,27}$. Limited evidence for postoperative response biomarkers to predict distant metastasis was established. Therefore, it is necessary and urgent to identify postoperative prognostic factor for distant metastasis to aid physicians to optimize systemic ACT and follow-up surveillance.

pCR represents well pathologic response to neoadjuvant treatment and postoperative CEA represents biological response to neoadjuvant therapy and curative resection. Both of them have been identified as important prognostic factors in rectal cancer patients ${ }^{11,26}$. The present study showed that patients with a postoperative CEA value more than $2.78 \mathrm{ng} / \mathrm{ml}$ had poor prognosis and $\mathrm{pCR}$ confirmed its prognostic value in identifying patients with various survival outcomes. To further stratify patients at high risk for distant metastasis, pCR and postoperative CEA were cooperated and the integrated model was showed an enhanced prognostic value. The present study is the largest study, to our knowledge, that assesses the association between integrated model and survival outcomes in patients with locally advanced rectal cancer.

The integrated model of $\mathrm{pCR}$ and postoperative CEA in our study effectively stratified locally advanced rectal cancer patients into three response subgroups. Patients with Group 4 (without pCR and higher postoperative CEA), Group 3 (without pCR and lower post-operative CEA), and Group 1 and 2 (with pCR) had the worst, intermediate, and best 3-year DMFS and DFS, respectively. These finding seems reasonable because pCR indicates tumor eradication and well response to treatment. Thus, patients with $\mathrm{pCR}$ had similar survival outcomes regardless of the level of postoperative CEA. Although CEA has been considered to promote metastasis ${ }^{28}$ and cause treatment resistance through inhibition of programmed cell death ${ }^{29}$, induction of cytokines ${ }^{30}$ that promote cancer cell survival, inhibition of inflammatory responses $^{31}$, and increased cell adhesion ${ }^{32}$, higher level of postoperative CEA in patients with pCR may be caused by other non-cancer related conditions. The current study supports the notion that a $\mathrm{PCR}$ is associated with excellent clinical outcome and represents a strong positive prognostic factor, and extensive efforts has been undertaken to improve the rate of $\mathrm{pCR}$. The concept of total neoadjuvant therapy (TNT) is to administer chemoradiation and chemotherapy prior to resection, which aim to reduce the risk of micrometastases. Moreover, clinical evidence and phase II clinical trials demonstrated that TNT improved the compliance rates and the incidence of $\mathrm{pCR}^{33,34}$. Furthermore, a phase III, randomized clinical trial NCT03177382 has been ongoing to compare TNT plus surgery with standard treatment. Other attempts to intensify neoadjuvant therapy have been investigated. The addition of oxaliplatin to concurrent chemoradiation is well known to achieve promising rate of $\mathrm{pCR}^{24}$, and the introduction of immunotherapy to neoadjuvant treatment (NCT03854799, NCT04109755) might further improve the pCR rates and prognosis. However, patients without $\mathrm{PCR}$ and higher post-operative CEA had poorest treatment outcomes since neither pathologic nor biological response was promising. Overall, this is the first study to support the integration of response biomarkers- PCR and postoperative CEA as a prognostic tool using an intelligence platform. 
Although ACT has been recommended in patients with locally advanced rectal cancer, the role of ACT remains to be defined due to many challenges ${ }^{35}$ especially suboptimal compliance to complete chemotherapy on ACT. Thus, we further verified the prognostic utility of our integrated model among patients treated with different durations of ACT. The current integrated model classified patients underwent $<3$ months of ACT into two response subgroups based on the risk of distant metastasis: lowrisk (Group 1, 2, and 3), and high-risk (Group 4). Patients in Group 1 and 2 were sensitive to neoadjuvant therapy, achieved pCR and had the lowest risk of distant metastases. For Group 3 patients, the risk of distant metastasis was reduced by short duration of ACT; thus, there is no significant difference in risk of distant disease failure between low risk group (Group 1,2) and intermediate risk group (Group 3). Additionally, among patients receiving $\geq 3$ months of ACT, the integrated model failed to classify patients in Group 3 and Group 4, which seemed reasonable. Reinforced ACT may eradicate the micrometastatic loci to reduce the risk of distant metastasis for poor-response subgroup (Group 4) patients, which led to similar DMFS among patients between Group 3 and Group 4.

The present integrated model of response biomarkers is effective to predict survival and provided a way to explore appropriate therapeutic strategies for locally advanced rectal cancer patients. Consistent with numerous previous studies, the present research demonstrated that pathologic response biomarker- $\mathrm{pCR}$ is a beneficial prognostic factor. Therefore, intensification of neoadjuvant therapy to increase the incidence of $\mathrm{pCR}$ is suggested. TNT, more intensive chemoradiation or immunotherapy combined with chemoradiation might be alternative and should be encouraged to be investigated in clinical trials. The National Comprehensive Cancer Network (NCCN) guidelines recommend ACT for all patients receiving neoadjuvant therapy ${ }^{36}$. Nevertheless, more concern about risk-adopted ACT strategy has been raised and investigated $^{22,37}$. For patients who did not achieve PCR, biological response biomarker- postoperative CEA classify patients into two groups. Similar to IDEA trials ${ }^{38}$ and a recent Veterans Health Administration analysis for locally advanced rectal cancer ${ }^{22}$, our study indicated that short duration of ACT ( $<3$ months) might be sufficient for patients at intermediate risk after neoadjuvant treatment and curative resection. In contrast, more aggressive ACT therapy ( $\geq 3$ months) was suggested for high risk patient to reduce the rate of distant metastasis.

The current study is the largest study to show the prognostic value and clinical applicability of the integrated model of pathologic response biomarker-pCR and biological response biomarkerpostoperative CEA in locally advanced rectal cancer. However, several limitations of our study exist. First, this retrospective study has inevitable bias. Multi-institutional prospective studies are warranted to validate our findings in the future. Second, some portion of patients received neoadjuvant chemotherapy alone. However, our integrated model only cooperated postoperative response biomarkers after neoadjuvant treatment, which would be crucial to determine the administration of ACT and the following surveillance. Third, no evidence about the role of ACT on patients with PCR was provided due to limited sample of patients not undergoing ACT. Finally, other prognostic factors, such as circumferential resection margin, extramural vascular invasion (EMVI), perineural invasion (PNI), tumor deposit and molecular subtypes are warranted to achieve better predictions in prognosis. Above factors should be 
included to establish effective nomograms to validate our findings in the future prospective multicenter studies.

\section{Conclusion}

The integrated pathologic response biomarker- $\mathrm{pCR}$ and biological response biomarker-postoperative CEA model predicts treatment outcomes more precisely, stratifies patients with different duration of ACT into different risk groups, and might aid clinicians to individualize ACT strategies to improve survival outcomes for locally advanced rectal cancer patients.

\section{Abbreviations}

\begin{tabular}{ll} 
Pathological complete response & $\mathrm{PCR}$ \\
\hline carcinoembryonic antigen & $\mathrm{CEA}$ \\
\hline receiver operating characteristic & $\mathrm{ROC}$ \\
\hline distant metastasis-free survival & $\mathrm{DMFS}$ \\
\hline disease-free survival & $\mathrm{DFS}$ \\
\hline adjuvant chemotherapy & $\mathrm{ACT}$ \\
\hline chemoradiotherapy & $\mathrm{CRT}$ \\
\hline total mesorectal excision & $\mathrm{TME}$ \\
\hline tumor-node-metastasis & $\mathrm{TNM}$ \\
\hline clinical target volume & $\mathrm{CTV}$ \\
\hline hazard ratios & $\mathrm{HRs}$ \\
\hline confidence intervals & $\mathrm{Cls}$ \\
\hline body mass index & $\mathrm{BMI}$ \\
\hline extramural vascular invasion & $\mathrm{EMVI}$ \\
\hline perineural invasion & $\mathrm{PNI}$
\end{tabular}

\section{Declarations}

\section{Funding}

This work was supported by National Natural Science Foundation of China (Grant No. 81802441, 81703060), Natural Science Foundation of Guangdong Province (Grant No. 2017A030310644), China Postdoctoral Science Foundation funded project (Grant No. 2018T110911), the National Key Research and Development Program of China (N0.2017YFC1308800), Science and Technology Planning Project of 
Guangdong Province (No. 201803040019, 20160916, 2014SC111), Key-Area Research and Development Program of Guangdong Province (2019B020229002), the Guangzhou Science and Technology Plan Project (201902020009), and National Key Clinical Discipline.

\section{Ethics approval and consent to participate}

Our study was approved by the Ethics Committee of Sun Yat-sen University, the Sixth Affiliated Hospital.

\section{Consent for publication}

Not applicable

\section{Availability of data and materials}

The data used and/or analyzed during the current study are available from the corresponding author on reasonable request.

\section{Competing interests}

We declare no potential conflicts of interest.

\section{Acknowledgement}

We thank the staff members and appreciate their efforts at Medio Labs, a company that concentrates on the processing of medical data processing and the utilization of medical technology, for the establishment of the Medio Labs Intelligence Platform.

\section{AUTHOR CONTRIBUTIONS}

Conception and design: Ping Lan, Yi-Kan Cheng, Shu-Biao Ye

Financial support: Ping Lan, Yi-Kan Cheng, Shu-Biao Ye

Provision of study materials or patients: Ping Lan,

Collection and assembly of data: Yi-Kan Cheng, Shu-Biao Ye, Dong-Wen Cheng, Pei-Si Li, Zhen-Sen Lin, Jia-Hui Long

Data analysis and interpretation: Yi-Kan Cheng, Shu-Biao Ye, Ping Lan

Manuscript writing: All authors

Final approval of manuscript: All authors

\section{References}


1. Bosset JF, Collette L, Calais G, Mineur L, Maingon P, Radosevic-Jelic L, Daban A, Bardet E, Beny A, Ollier JC, Trial ERG. Chemotherapy with preoperative radiotherapy in rectal cancer. The New England journal of medicine 2006;355(11): 1114-1123.

2. Collette L, Bosset JF, den Dulk M, Nguyen F, Mineur L, Maingon P, Radosevic-Jelic L, Pierart M, Calais G, European Organisation for R, Treatment of Cancer Radiation Oncology G. Patients with curative resection of cT3-4 rectal cancer after preoperative radiotherapy or radiochemotherapy: does anybody benefit from adjuvant fluorouracil-based chemotherapy? A trial of the European Organisation for Research and Treatment of Cancer Radiation Oncology Group. Journal of clinical oncology : official journal of the American Society of Clinical Oncology 2007;25(28): 4379-4386.

3. Peeters KC, Marijnen CA, Nagtegaal ID, Kranenbarg EK, Putter H, Wiggers T, Rutten H, Pahlman L, Glimelius B, Leer JW, van de Velde CJ, Dutch Colorectal Cancer G. The TME trial after a median follow-up of 6 years: increased local control but no survival benefit in irradiated patients with resectable rectal carcinoma. Ann Surg 2007;246(5): 693-701.

4. Sebag-Montefiore D, Stephens RJ, Steele R, Monson J, Grieve R, Khanna S, Quirke P, Couture J, de Metz C, Myint AS, Bessell E, Griffiths G, Thompson LC, Parmar M. Preoperative radiotherapy versus selective postoperative chemoradiotherapy in patients with rectal cancer (MRC CR07 and NCIC-CTG C016): a multicentre, randomised trial. Lancet 2009;373(9666): 811-820.

5. Hutter RV. At last-worldwide agreement on the staging of cancer. Archives of surgery 1987;122(11): 1235-1239.

6. Merkel S, Mansmann U, Papadopoulos T, Wittekind C, Hohenberger W, Hermanek P. The prognostic inhomogeneity of colorectal carcinomas Stage III: a proposal for subdivision of Stage III. Cancer 2001;92(11): 2754-2759.

7. Greene FL, Stewart AK, Norton HJ. A new TNM staging strategy for node-positive (stage III) colon cancer: an analysis of 50,042 patients. Ann Surg 2002;236(4): 416-421; discussion 421.

8. Fokas E, Liersch T, Fietkau R, Hohenberger W, Beissbarth T, Hess C, Becker H, Ghadimi M, Mrak K, Merkel S, Raab HR, Sauer R, Wittekind C, Rodel C. Tumor regression grading after preoperative chemoradiotherapy for locally advanced rectal carcinoma revisited: updated results of the CAO/ARO/AIO-94 trial. Journal of clinical oncology : official journal of the American Society of Clinical Oncology 2014;32(15): 1554-1562.

9. Maas M, Nelemans PJ, Valentini V, Das P, Rodel C, Kuo LJ, Calvo FA, Garcia-Aguilar J, Glynne-Jones R, Haustermans K, Mohiuddin M, Pucciarelli S, Small W, Jr., Suarez J, Theodoropoulos G, Biondo S, Beets-Tan RG, Beets GL. Long-term outcome in patients with a pathological complete response after chemoradiation for rectal cancer: a pooled analysis of individual patient data. Lancet Oncol 2010;11(9): 835-844.

10. Martin ST, Heneghan HM, Winter DC. Systematic review and meta-analysis of outcomes following pathological complete response to neoadjuvant chemoradiotherapy for rectal cancer. The British journal of surgery 2012;99(7): 918-928. 
11. de Campos-Lobato LF, Stocchi L, da Luz Moreira A, Geisler D, Dietz DW, Lavery IC, Fazio VW, Kalady MF. Pathologic complete response after neoadjuvant treatment for rectal cancer decreases distant recurrence and could eradicate local recurrence. Annals of surgical oncology 2011;18(6): 1590-1598.

12. Valentini V, van Stiphout RG, Lammering G, Gambacorta MA, Barba MC, Bebenek M, Bonnetain F, Bosset JF, Bujko K, Cionini L, Gerard JP, Rodel C, Sainato A, Sauer R, Minsky BD, Collette L, Lambin P. Nomograms for predicting local recurrence, distant metastases, and overall survival for patients with locally advanced rectal cancer on the basis of European randomized clinical trials. Journal of clinical oncology : official journal of the American Society of Clinical Oncology 2011;29(23): 3163-3172.

13. Takagawa R, Fujii S, Ohta M, Nagano Y, Kunisaki C, Yamagishi S, Osada S, Ichikawa Y, Shimada H. Preoperative serum carcinoembryonic antigen level as a predictive factor of recurrence after curative resection of colorectal cancer. Annals of surgical oncology 2008;15(12): 3433-3439.

14. Thirunavukarasu P, Sukumar S, Sathaiah M, Mahan M, Pragatheeshwar KD, Pingpank JF, Zeh H, 3rd, Bartels CJ, Lee KK, Bartlett DL. C-stage in colon cancer: implications of carcinoembryonic antigen biomarker in staging, prognosis, and management. Journal of the National Cancer Institute 2011;103(8): 689-697.

15. Kim CW, Yoon YS, Park IJ, Lim SB, Yu CS, Kim JC. Elevation of preoperative s-CEA concentration in stage IIA colorectal cancer can also be a high risk factor for stage II patients. Annals of surgical oncology 2013;20(9): 2914-2920.

16. Tarantino I, Warschkow R, Worni M, Merati-Kashani K, Koberle D, Schmied BM, Muller SA, Steffen T, Cerny T, Guller U. Elevated preoperative CEA is associated with worse survival in stage I-III rectal cancer patients. British journal of cancer 2012;107(2): 266-274.

17. Park YA, Lee KY, Kim NK, Baik SH, Sohn SK, Cho CW. Prognostic effect of perioperative change of serum carcinoembryonic antigen level: a useful tool for detection of systemic recurrence in rectal cancer. Annals of surgical oncology 2006;13(5): 645-650.

18. Lin JK, Lin CC, Yang SH, Wang HS, Jiang JK, Lan YT, Lin TC, Li AF, Chen WS, Chang SC. Early postoperative CEA level is a better prognostic indicator than is preoperative CEA level in predicting prognosis of patients with curable colorectal cancer. International journal of colorectal disease 2011;26(9): 1135-1141.

19. O'Connell MJ, Mailliard JA, Kahn MJ, Macdonald JS, Haller DG, Mayer RJ, Wieand HS. Controlled trial of fluorouracil and low-dose leucovorin given for 6 months as postoperative adjuvant therapy for colon cancer. Journal of clinical oncology : official journal of the American Society of Clinical Oncology 1997;15(1): 246-250.

20. Andre T, Boni C, Navarro M, Tabernero J, Hickish T, Topham C, Bonetti A, Clingan P, Bridgewater J, Rivera F, de Gramont A. Improved overall survival with oxaliplatin, fluorouracil, and leucovorin as adjuvant treatment in stage II or III colon cancer in the MOSAIC trial. Journal of clinical oncology : official journal of the American Society of Clinical Oncology 2009;27(19): 3109-3116.

21. Twelves C, Wong A, Nowacki MP, Abt M, Burris H, 3rd, Carrato A, Cassidy J, Cervantes A, Fagerberg J, Georgoulias V, Husseini F, Jodrell D, Koralewski P, Kroning H, Maroun J, Marschner N, McKendrick J, 
Pawlicki M, Rosso R, Schuller J, Seitz JF, Stabuc B, Tujakowski J, Van Hazel G, Zaluski J, Scheithauer W. Capecitabine as adjuvant treatment for stage III colon cancer. The New England journal of medicine 2005;352(26): 2696-2704.

22. Spiegel DY, Boyer MJ, Hong JC, Williams CD, Kelley MJ, Salama JK, Palta M. Survival Advantage With Adjuvant Chemotherapy for Locoregionally Advanced Rectal Cancer: A Veterans Health Administration Analysis. J Natl Compr Canc Netw 2020;18(1): 52-58.

23. Bujko K, Glynne-Jones R, Bujko M. Does adjuvant fluoropyrimidine-based chemotherapy provide a benefit for patients with resected rectal cancer who have already received neoadjuvant radiochemotherapy? A systematic review of randomised trials. Annals of oncology : official journal of the European Society for Medical Oncology 2010;21(9): 1743-1750.

24. Deng Y, Chi P, Lan P, Wang L, Chen W, Cui L, Chen D, Cao J, Wei H, Peng X, Huang Z, Cai G, Zhao R, Huang Z, Xu L, Zhou H, Wei Y, Zhang H, Zheng J, Huang Y, Zhou Z, Cai Y, Kang L, Huang M, Wu X, Peng J, Ren D, Wang J. Neoadjuvant Modified FOLFOX6 With or Without Radiation Versus Fluorouracil Plus Radiation for Locally Advanced Rectal Cancer: Final Results of the Chinese FOWARC Trial. Journal of clinical oncology : official journal of the American Society of Clinical Oncology 2019;37(34): 3223-3233.

25. Zhang J, Huang M, Cai Y, Wang L, Xiao J, Lan P, Hu H, Wu X, Ling J, Peng J, Chen D, Kang L, Zhang Y, Ren D, Wang H, Chen S, Lin F, Zheng J, Zhou Z, Wang J, Deng Y. Neoadjuvant Chemotherapy With mFOLFOXIRI Without Routine Use of Radiotherapy for Locally Advanced Rectal Cancer. Clinical colorectal cancer 2019;18(4): 238-244.

26. Jeong S, Nam TK, Jeong JU, Kim SH, Kim K, Jang HS, Jeong BK, Lee JH. Postoperative carcinoembryonic antigen level has a prognostic value for distant metastasis and survival in rectal cancer patients who receive preoperative chemoradiotherapy and curative surgery: a retrospective multi-institutional analysis. Clinical \& experimental metastasis 2016;33(8): 809-816.

27. Sauer R, Liersch T, Merkel S, Fietkau R, Hohenberger W, Hess C, Becker H, Raab HR, Villanueva MT, Witzigmann H, Wittekind C, Beissbarth T, Rodel C. Preoperative versus postoperative chemoradiotherapy for locally advanced rectal cancer: results of the German CAO/ARO/AIO-94 randomized phase III trial after a median follow-up of 11 years. Journal of clinical oncology : official journal of the American Society of Clinical Oncology 2012;30(16): 1926-1933.

28. Hostetter RB, Augustus LB, Mankarious R, Chi KF, Fan D, Toth C, Thomas P, Jessup JM. Carcinoembryonic antigen as a selective enhancer of colorectal cancer metastasis. Journal of the National Cancer Institute 1990;82(5): 380-385.

29. Samara RN, Laguinge LM, Jessup JM. Carcinoembryonic antigen inhibits anoikis in colorectal carcinoma cells by interfering with TRAIL-R2 (DR5) signaling. Cancer research 2007;67(10): 47744782.

30. Gangopadhyay A, Bajenova O, Kelly TM, Thomas P. Carcinoembryonic antigen induces cytokine expression in Kuppfer cells: implications for hepatic metastasis from colorectal cancer. Cancer research 1996;56(20): 4805-4810. 
31. Jessup JM, Laguinge L, Lin S, Samara R, Aufman K, Battle P, Frantz M, Edmiston KH, Thomas P. Carcinoembryonic antigen induction of IL-10 and IL-6 inhibits hepatic ischemic/reperfusion injury to colorectal carcinoma cells. International journal of cancer 2004;111(3): 332-337.

32. Benchimol S, Fuks A, Jothy S, Beauchemin N, Shirota K, Stanners CP. Carcinoembryonic antigen, a human tumor marker, functions as an intercellular adhesion molecule. Cell 1989;57(2): 327-334.

33. Ludmir EB, Palta M, Willett CG, Czito BG. Total neoadjuvant therapy for rectal cancer: An emerging option. Cancer 2017;123(9): 1497-1506.

34. Cercek A, Roxburgh CSD, Strombom P, Smith JJ, Temple LKF, Nash GM, Guillem JG, Paty PB, Yaeger R, Stadler ZK, Seier K, Gonen M, Segal NH, Reidy DL, Varghese A, Shia J, Vakiani E, Wu AJ, Crane CH, Gollub MJ, Garcia-Aguilar J, Saltz LB, Weiser MR. Adoption of Total Neoadjuvant Therapy for Locally Advanced Rectal Cancer. JAMA oncology 2018;4(6): e180071.

35. Carvalho C, Glynne-Jones R. Challenges behind proving efficacy of adjuvant chemotherapy after preoperative chemoradiation for rectal cancer. Lancet Oncol 2017;18(6): e354-e363.

36. Benson AB, Venook AP, Al-Hawary MM, Cederquist L, Chen YJ, Ciombor KK, Cohen S, Cooper HS, Deming D, Engstrom PF, Grem JL, Grothey A, Hochster HS, Hoffe S, Hunt S, Kamel A, Kirilcuk N, Krishnamurthi S, Messersmith WA, Meyerhardt J, Mulcahy MF, Murphy JD, Nurkin S, Saltz L, Sharma S, Shibata D, Skibber JM, Sofocleous CT, Stoffel EM, Stotsky-Himelfarb E, Willett CG, Wuthrick E, Gregory KM, Gurski L, Freedman-Cass DA. Rectal Cancer, Version 2.2018, NCCN Clinical Practice Guidelines in Oncology. J Natl Compr Canc Netw 2018;16(7): 874-901.

37. Glynne-Jones R, Wyrwicz L, Tiret E, Brown G, Rodel C, Cervantes A, Arnold D, Committee EG. Rectal cancer: ESMO Clinical Practice Guidelines for diagnosis, treatment and follow-up. Annals of oncology : official journal of the European Society for Medical Oncology 2017;28(suppl_4): iv22-iv40.

38. Andre T, Vernerey D, Mineur L, Bennouna J, Desrame J, Faroux R, Fratte S, Hug de Larauze M, PagetBailly S, Chibaudel B, Bez J, Dauba J, Louvet C, Lepere C, Dupuis O, Becouarn Y, Mabro M, Egreteau J, Bouche O, Deplanque G, Ychou M, Galais MP, Ghiringhelli F, Dourthe LM, Bachet JB, Khalil A, Bonnetain F, de Gramont A, Taieb J, for Prodige investigators GFFdCD, Unicancer. Three Versus 6 Months of Oxaliplatin-Based Adjuvant Chemotherapy for Patients With Stage III Colon Cancer: Disease-Free Survival Results From a Randomized, Open-Label, International Duration Evaluation of Adjuvant (IDEA) France, Phase III Trial. Journal of clinical oncology : official journal of the American Society of Clinical Oncology 2018;36(15): 1469-1477.

\section{Figures}




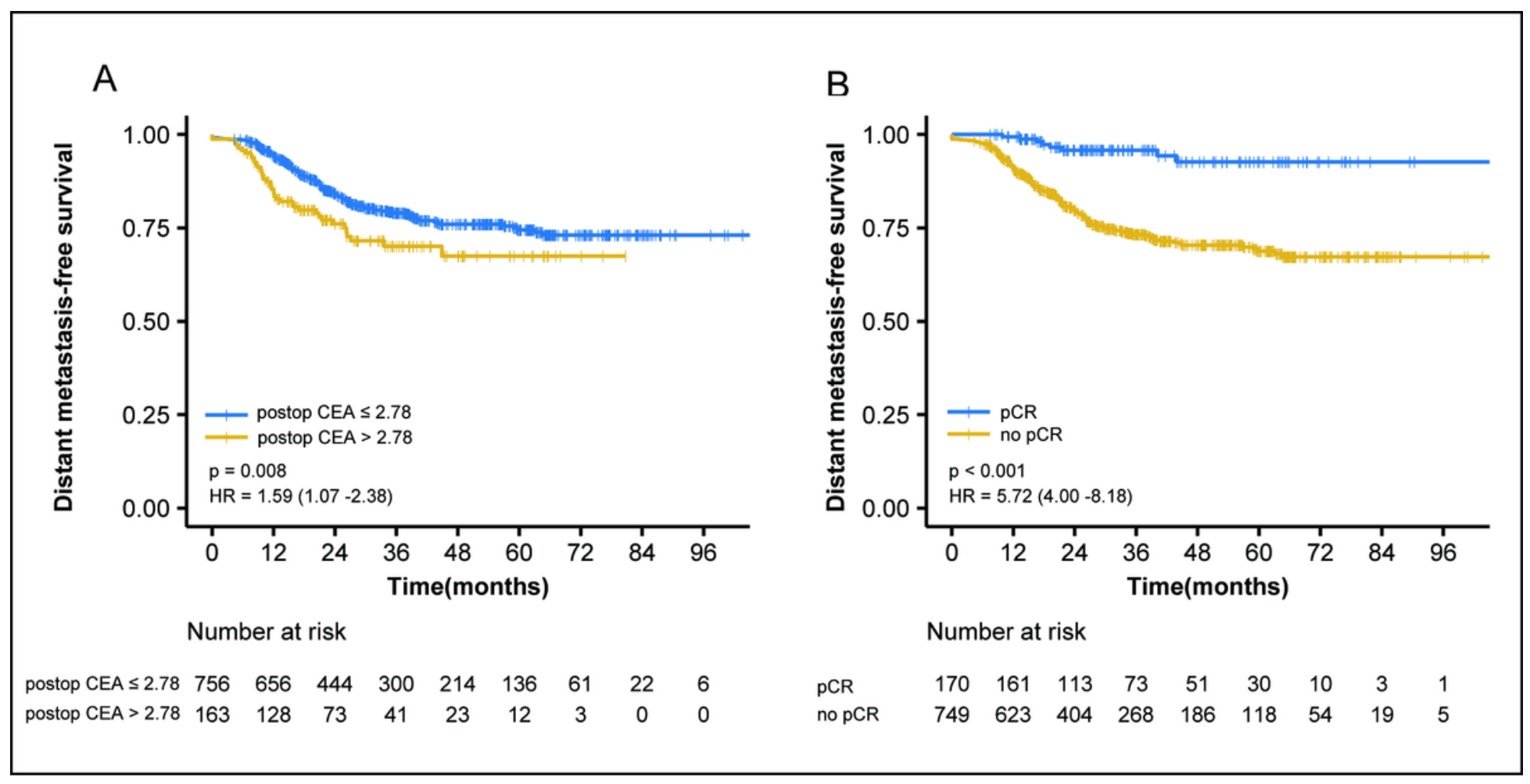

\section{Figure 1}

Distant metastasis-free survival analysis for PCR (a) and postoperative CEA (b) for the prognostic prediction. PCR, pathological complete response; postop CEA, postoperative carcinoembryonic antigen. 


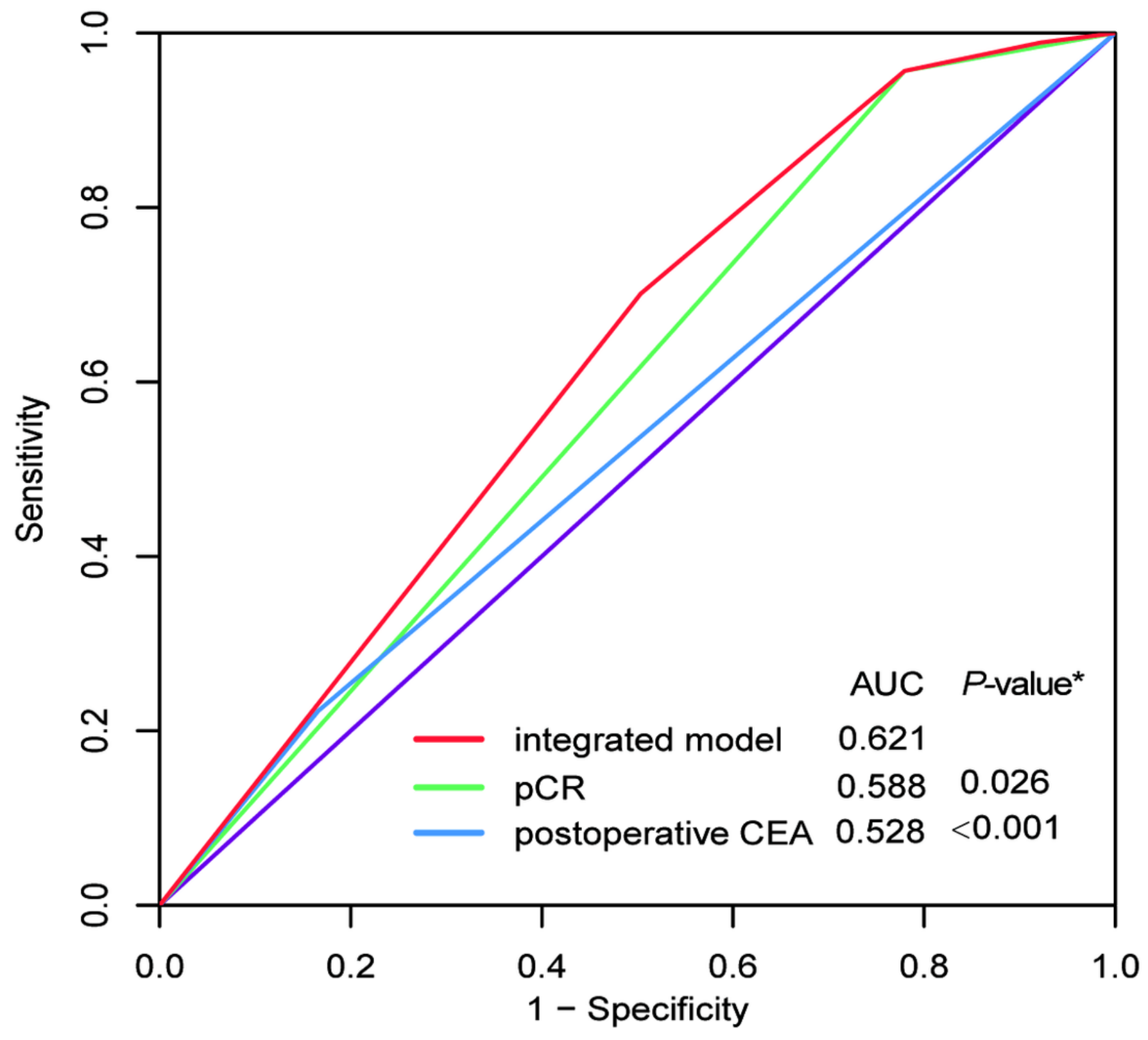

Figure 2

ROC curves for the cut-off points for pCR, postoperative CEA, and the integrated model. *Compared with the integrated model. pCR, pathological complete response; postop CEA, postoperative carcinoembryonic antigen; ROC, receiver operator characteristic. 


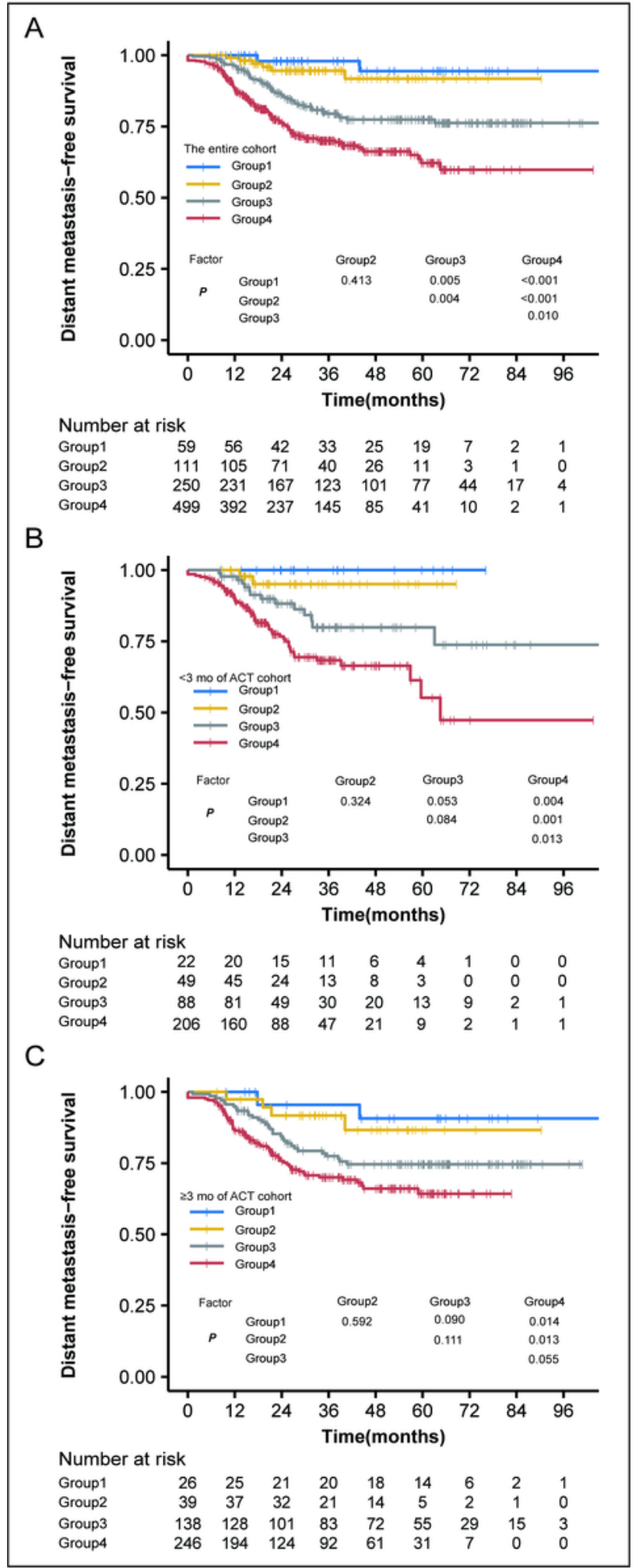

Figure 3

Survival analysis using the integrated model of $\mathrm{pCR}$ and postoperative CEA for the prognostic prediction of DMFS in all patients (a), and patients receiving $<3$ months of ACT (b) or patients receiving $\geq 3$ months (c) of ACT. Group 1 (patients with pCR and postoperative CEA $\leqslant 2.78 \mathrm{ng} / \mathrm{ml}$ ), Group 2 (patients with pCR and postoperative CEA $>2.78 \mathrm{ng} / \mathrm{ml}$ ), Group 3 (patients with no pCR and postoperative CEA $\leqslant 2.78 \mathrm{ng} / \mathrm{ml}$ ), and Group 4 (patients with no pCR and postoperative CEA >2.78 ng/ml). DMFS, distant metastasis-free 
survival; pCR, pathological complete response; postop CEA, postoperative carcinoembryonic antigen; ACT, adjuvant chemotherapy. mo, months.

\section{Supplementary Files}

This is a list of supplementary files associated with this preprint. Click to download.

- supplementaryappendix.docx 